\title{
ACERCA DE LAS DIFERENCIAS ENTRE LOS DERECHOS Y LIBERTADES CLÁSICOS Y LOS DERECHOS SOCIALES*
}

\author{
José Ignacio Martínez Estay \\ Doctor en Derecho \\ Profesor de Derecho Constitucional de la Universidad Adolfo Ibáñez.
}

\section{Introducción.}

En el presente trabajo se analizará una cuestión de gran relevancia en la teoría de los derechos fundamentales, que no es otra que la problemática de sus límites. Los derechos y libertades constitucionales no son ilimitados, a pesar que algunos de ellos son absolutos. $Y$ esto no es un contrasentido, pues ambas cosas tienen distinta significación, según se verá, Pero a su vez, no son iguales los límites de los derechos y libertades clásicos que los de los derechos sociales, lo que en gran medida se debe precisamente a que unos son absolutos y otros no. Todas estas cuestiones serán tratadas a continuación.

\section{Carácter absoluto y límites de los derechos y libertades clásicos.}

Como recuerda Pereira Menaut, los derechos y libertades clásicos se caracterizan particularmente por su carácter absoluto ${ }^{57}$. Pero aquello no significa que no tengan límites, "pues tal cosa no sería natural, ni posible, ni fue esa la intención de los iniciadores del constitucionalismo, ni sería compatible con el sentido común" ${ }^{\text {58 }}$. Eso es lo que lleva implícito la sentencia del Juez Holmes, en el caso Schenk v. United States del año 1919, cuando resolvió que "la libertad de expresión aun siendo sagrada en los Estados Unidos, no da derecho a gritar 'ifuego!' en un teatro abarrotado de público" ${ }^{159}$.

\footnotetext{
- Este trabajo está basado en el libro del mismo autor, titulado Jurisprudencia constitucional española sobre derechos sociales, Barcelona, Cedecs, 1997, versión corregida y adaptada de la tesis doctoral del mismo nombre, defendida en 1996 en la Universidad de Santiago de Compostela, Galicia, España.

${ }^{57}$ Pereira Menaut, Antonio Carlos: Lecciones de Teoría Constitucional, Madrid, Edersa, 1987, 293 y ss. Isaiah Berlin recuerda que en la concepción liberal clásica (Mill, Constant, Tocqueville) el carácter absoluto de los derechos es requisito sine quanon de una sociedad libre; en Two concepts of liberty, London, Oxford University Press, 1958, 51. Sin embargo, para Teresa Freixes Sanjuán los derechos no tienen carácter absoluto; en Constitución y Derechos Fundamentales, Barcelona, PPU, 1992, 86. En este mismo sentido ver de Castro Cid, Benito: Los derechos económicos, sociales y culturales, León, Universidad de León, 1993, 29 (nota 16).

${ }^{58}$ Pereira: Lecciones..., 294. Un enfoque distinto acerca de los límites de los derechos puede consultarse en Aguiar: "Los límites de los Derechos Fundamentales", 9-34. Este estudio se refiere a los limites de los derechos fundamentales de la Constitución española, entendiendo por tales los propios del ámbito del artículo 53.1. El trabajo parte de la base de que no es posible considerar que los derechos sean a la vez absolutos pero limitados, cuestión que no comparto. Y es que el carácter absoluto de un derecho no significa que sea ilimitado, como se verá más adelante.

${ }^{59}$ Pereira: Lecciones..., 294.
} 
$Y$ es que como destaca Ignacio de Otto, "cualquier derecho o libertad, fundamental o no, ampara aquello que ampara y nada más". Esta afirmación queda muy bien ilustrada a través de algunas situaciones planteadas por el mismo autor. Así por ejemplo, en el caso "de la prohibición de utilizar explosivos para hacer una obra de arte 0 en la de instalar un laboratorio peligroso en una vivienda, nos hallamos ante normas que no regulan supuestos de hecho pertenecientes al derecho fundamental, sino de otra naturaleza, aunque puedan guardar una ocasional relación con el derecho propiamente dicho. La sanción de un eventual incendio neroniano no es limitación del arte, sino sanción de un incendio ${ }^{160}$.

Asimismo, el Tribunal Constitucional español, en una de sus primeras sentencias, la 11/1981, de 8 de abril, declaró que "ningún derecho, ni aun los de naturaleza o carácter constitucional, pueden considerarse como ilimitados" (fundamento jurídico 7). Más aun, la "Constitución establece por sí misma los límites de los derechos fundamentales en algunas ocasiones. En otras ocasiones el límite del derecho deriva de la Constitución sólo de una manera mediata o indirecta, en cuanto que ha de justificarse por la necesidad de proteger o preservar no sólo otros derechos constitucionales, sino también otros bienes constitucionalmente protegidos" (fundamento jurídico 7). Similar pronunciamiento fue emitido por el alto Tribunal en las sentencias 2/1982, de 29 de enero, y 91/1983, de 7 de noviembre.

Entonces ¿qué significa que los derechos y libertades clásicos tienen un carácter absoluto? Si se sigue a Pereira Menaut, puede decirse que el carácter absoluto de los derechos y libertades clásicos consiste:

1. En que estos derechos y libertades sólo pueden ser limitados por casos excepcionales, y en ningún caso los Estados pueden "legislar o seguir una política estable que atente contra alguno de los derechos" ${ }^{16}$. Y es que quizá el carácter absoluto de estos derechos se manifiesta con más fuerza que en ningún otro aspecto en la relación de ellos con el poder, cuya máxima manifestación desde el siglo XVII es el Estado. Es bien sabido que el poder (al igual que estos derechos) es también absoluto, y el constitucionalismo nació para limitarlo y proteger así los derechos y libertades. Porque estos derechos se satisfacen por su no entorpecimiento, y los inventores del constitucionalismo advirtieron que el mayor entorpecimiento para aquéllos era el poder.

2. En que protegen realidades pre-jurídicas como la vida o la libertad ${ }^{62}$, a las que el reconocimiento por el Derecho Positivo "no quita ni añade nada intrínseco "'63,

3. En que su reconocimiento o falta del mismo por las costumbres y la opinión dominante, "tampoco les quita ni añade nada intrínseco" 64.

\footnotetext{
${ }^{60}$ de Otto, Ignacio: "La regulación del ejercicio de los derechos y libertades. La garantía de su contenido esencial en el artículo 53.1 de la Constitución", en Martín Retortillo y de Otto: Derechos fundamentales y Constitución, Madrid, Civitas, 1988,150 y 146. Por todo ello, no parece necesario recurrir a la institución del "abuso del derecho" para explicar por qué una acción no se encuentra amparada por un derecho. Sin embargo, el Tribunal Constitucional español ha acudido a esa figura en varias sentencias, como la 120/1983, de 15 de diciembre, la 41/1984, de 21 de marzo o la 88/1985, de 19 de julio.

${ }^{61}$ Pereira: Lecciones..., 294.

${ }_{63}^{6} \mathrm{Al}$ decir pre-jurídicas se quiere resaltar que se trata de realidades anteriores y superiores al ordenamiento jurídico.

${ }^{63}$ Ibid., 294.

${ }^{64}$ Ibid., 295.
} 
4. En que, finalmente, dichos derechos son "un valor absoluto para el constitucionalismo, siendo elementos inherentes, imprescindibles, esenciales para la propia idea de Constitución" 65 , la que fue inventada para protegerlos.

\section{Carácter no absoluto y límites de los derechos y libertades clásicos.}

En cambio los derechos sociales no tienen ese carácter absoluto que presentan los clásicos. Si respecto de éstos el Estado no puede llevar a cabo una política que de manera permanente atente en su contra, no sucede lo mismo con los derechos que ahora nos ocupan. Gran parte de los derechos sociales consisten en prestaciones; más aún, prestaciones generalmente a cargo del Estado. Y justamente el propio carácter prestacional de gran parte de estos derechos, determina que no posean un carácter absoluto, y que sus límites sean distintos que los de los derechos clásicos. Concretamente ello se debe a varias razones:

1. La primera, y quizá la más importante, dice relación con los recursos económicos del Estado. Puesto que gran parte de los derechos sociales se materializan en prestaciones, el principal obligado a ellas, o sea el Estado, necesita contar con los recursos económicos indispensables para llevarlas a cabo66. Pero el Estado, como cualquier agente económico, no puede sustraerse al problema básico sobre el que se estructura la ciencia económica: la escasez de los recursos67. Esta regla de oro de la economía, constituye una gran limitante para la plena realización de los derechos sociales, y así lo ha entendido el Tribunal Europeo de Derechos Humanos en el denominado "Caso Airey". En él, el Tribunal señaló que "la progresiva realización de los derechos sociales y económicos depende de la situación de cada Estado, y sobre todo de su situación económica" ${ }^{16}$.

La misma línea jurisprudencial, aunque formulada quizá más contundentemente, ha sido adoptada por el Tribunal Constitucional español, en su sentencia $77 / 1985$, de 27 de junio. En ésta señaló que "el legislador se encuentra ante la necesidad de conjugar, no sólo diversos valores y mandatos con la insoslayable limitación de los recursos disponibles" (fundamento jurídico 11). Esta misma idea fue reiterada en la sentencia 134/1987, de 21 de julio, al señalar que el Estado debe "administrar medios económicos limitados para un gran número de necesidades sociales" ${ }^{19}$. Podría decirse que esta jurisprudencia es una especie de ratificación del

\footnotetext{
${ }^{65}$ Ibid., 296.

${ }^{66}$ Así lo advirtió Piero Calamandrei en pleno proceso constituyente italiano, Ver Pace. Alejandro: "Derechos de Libertad y Derechos Sociales en el Pensamiento de Piero Calamandrei", Revista de Estudios Políticos 63, Madrid, $1989,55$.

${ }^{67}$ A propósito de España, Sánchez González y Pereira Menaut señalan que "la mayoría de los derechos económicos-sociales exige para su satisfacción la creación de una situación objetiva de prosperidad que de momento no existe". Ello sin perjuicio de los supuestos "en los que ni la riqueza puede auxiliarnos", como es el caso del derecho al medio ambiente"; en "Los derechos sociales y los principios rectores de la política social y económica", Revista de Derecho Político 36, Madrid, 1992, 262-263. Por su parte Vallespín Oña dice que la débil articulación de los derechos sociales "depende más de sus auténticas condiciones de posibilidad, el estado efectivo de los recursos económicos de una determinada sociedad, que de consideraciones de naturaleza jurídica"; en "Estado de bienestar y Constitución", Revista del Centro de Estudios Constitucionales 1, Madrid, $1988,131$.

68 Sentencia del Tribunal Europeo de Derechos Humanos de 9 de octubre de 1979. El Pacto Internacional de Derechos Económicos, Sociales y Culturales señala precisamente que la plena efectividad de estos derechos debe tenerse de manera progresiva, de acuerdo a los recursos que disponga cada Estado. En todo caso, dichos recursos deben ser utilizados al máximo (artículo 2.1).

${ }^{69}$ Véase también la sentencia $172 / 1989$, de 19 de octubre, que discurre en base al mismo razonamiento.
} 
viejo aforismo que señala que "al imposible nadie está obligado". Y a propósito de los derechos sociales, menos obligado puede estar el Estado a satisfacerlos cuando la economía está en crisis.

A este respecto Konrad Hesse señala que la fuerza normativa de la Constitución se halla condicionada en parte por la posibilidad de realización de sus contenidos. Si la Constitución no tiene en cuenta la realidad y lo posible, no sólo carecerá de carácter jurídico, sino que tampoco alcanzará eficacia política ${ }^{70}$.

En esa misma línea Carmona Cuenca destaca que la eficacia de los derechos sociales "depende no sólo de factores jurídicos sino sobre todo de factores económicos ${ }^{1171}$. Asimismo, Haba destaca que el cumplimiento de los derechos sociales depende fundamentalmente de los recursos económicos del Estado ${ }^{72}$. Esta misma idea es repetida por Vieira de Andrade, quien agrega que como la satisfacción de los derechos sociales depende de los recursos materiales del Estado, la Constitución no puede determinar su contenido. Por ello no puede encargarse a los jueces la concretización de estos derechos: se trata de cuestiones políticas, de competencia del legislador ordinario y de los órganos que tienen a su cargo la política general del Estado $^{73}$.

Por su parte, García Macho recuerda que en la doctrina alemana hay relativo consenso en torno a dos cuestiones. La primera consiste en que la capacidad de realización de los derechos sociales prestacionales depende "del grado de desarrollo económico", y la segunda en que el crecimiento económico no puede ser asegurado jurídicamente. Esto hace que "los derechos fundamentales sociales, por definición, están obligados por su carácter relativo".

Asimismo, el profesor García Macho resalta que "es necesario partir del principio básico de que la actividad social del Estado depende del desarrollo del producto social bruto y que este desarrollo exige esfuerzos extraordinarios tanto financieros como personales". Todo ello le lleva a entender los derechos sociales como Häberle, esto es, bajo reserva de lo posible, a fin de no amenazar la estabilidad de la Constitución $^{74}$.

El factor económico determina que incluso el significado de cada uno de estos derechos sea diferente en los países subdesarrollados que en los desarrollados. $Y$ aun entre éstos su situación también variará en relación a la situación económica de cada

\footnotetext{
${ }^{70}$ Hesse, Konrad: Escritos de Derecho Constitucional, Madrid, Centro de Estudios Constitucionales, 1992, 65, Y es que "donde la Constitución ignora las leyes espirituales, sociales, políticas o económicas de su época, carecerá del germen imprescindible de fuerza vital", siendo incapaz de hacer que llegue a producirse "el estado por ella dispuesto en contradicción con dicho estado de desarrollo". Todo ello sin perjuicio de que la fuerza normativa de la Constitución está también condicionada "por la voluntad constante de los implicados en el proceso constitucional de realizar los contenidos de la Constitución"; Hesse, 26.

${ }^{71}$ Carmona Cuenca, Encarnación: "Las Normas Constitucionales de Contenido Social: Delimitación y Problemática de su eficacia Jurídica ", Revista de Estudios Políticos 76, Madrid, 1992, 105.

12 Haba, Enrique: "Magia verbal, realidades y sentido fermental de los, así llamados, 'derechos' económicos", Sistema 125, Madrid, 1995, 61-62, 64.

${ }^{73}$ Vieira de Andrade: "Dereitos Fundamentais", Pólis-Enciclopedia Verbo da sociedade e do estado, Lisboa Verbo, 1984, vol II, 610.

74 García Macho, Ricardo: Las aporías de los derechos fundamentales sociales y el derecho a una vivienda, Madrid, Instituto de Estudios de Administración Local, 1982, 97-98, 143 y 110. Ana Poyal Costa también destaca la estrecha relación existente entre la realización de los derechos sociales y la situación económica del Estado; en "La Eficacia de los Derechos Humanos Frente a Terceros", Revista de Derecho Político 34, Madrid, 1991, 213.
} 
Estado $^{75}$. Incluso la capacidad financiera de un mismo país "puede sufrir oscilaciones importantes en plazos relativamente $\operatorname{cortos}^{176}$. En definitiva, la aceptación, y sobre todo el cumplimiento de los derechos sociales, dependen del grado de desarrollo de un país ${ }^{77}$.

Frente a esta innegable limitación, Contreras Peláez plantea que la solución debe buscarse a nivel internacional. A su juicio, la "comunidad internacional aparece como el único posible garante moral ( $y$, cuando su proceso de institucionalización esté más avanzado, hay que esperar también jurídico) de los derechos sociales en las regiones subdesarrolladas" ${ }^{78}$. Pero como se puede apreciar, aquello no es una solución jurídica sino política, lo que resulta clave para entender la problemática de los derechos sociales. No se le puede pedir al Derecho lo que está más allá de sus posibilidades, y que ni siquiera la política o la economía pueden asegurar.

2. Por otro lado, el carácter no absoluto de los derechos sociales se ve reforzado por otras consideraciones. Así por ejemplo, y a diferencia de los derechos liberales, por regla general los derechos sociales recogen más bien principios, programas o aspiraciones político-sociales, elevadas a nivel constitucional. Haba señala al respecto que los derechos sociales reflejan ideales o fines a los que se llama "derechos", y recuerda que una cosa es un ideal y otra la forma "en que éste logre repercutir sobre la realidad misma" ${ }^{79}$.

3. Asimismo, por tratarse de principios político-sociales o político-económicos, dependen en gran medida de las costumbres y opinión pública dominante. Piénsese por ejemplo en las "modas" o tendencias económicas del momento, las que ratifican que los derechos sociales están lejos de constituir un absoluto. Un buen ejemplo lo constituye la Europa comunitaria. Es un hecho que las políticas sociales han sido relegadas a un segundo plano, desplazadas por políticas económicas de ajuste, que apuntan a la igualación de las principales variables económicas de los países comunitarios 80 . Todo ello ha supuesto claras restricciones al gasto público, lo que repercute desfavorablemente en las prestaciones y servicios a cargo del Estado ${ }^{81}$.

${ }^{75}$ Mayorga Lorca señala que "siendo la realidad socioeconómica de América Latina diferente a la de las naciones industrializadas, los derechos económicos, sociales y culturales se expresan y tienen un alcance no del todo similar en ambas realidades, no obstante las diferencias que existen al interior de la propia latinoamérica"; en Naturaleza jurídica de los derechos económicos, sociales y culturales, Santiago, Editorial Jurídica de Chile, 1990, segunda edición, 24. En un sentido símilar ver de Castro, 170; también Haba, 64. En todo caso, para Contreras Peláez los derechos sociales pertenecen no sólo a los habitantes de países desarrollados, sino también a los de los demás países; en Derechos sociales. Teoría e ideología, Madrid, Tecnos, $1994,114-115$.

${ }^{76}$ Contreras, 112.

77 Mayorga, 34-35.

${ }^{78}$ Contreras, 120. A su juicio estos derechos "no son inviables por su propia naturaleza; sólo son inviables en tanto persista el actual modelo de distribución internacional del trabajo"; ibid., 12.

79 Haba, 65-66.

${ }^{80}$ Al respecto ver Rubio Lara, María Josefa: "La política social comunitaria y su incidencia en los Estados del Bienestar". Revista de la Facultad de Derecho de la Universidad Complutense 18, Madrid, 1994. 163-169.

${ }^{81}$ Por eso no deja de tener razón Vallespin Oña al señalar que tanto O'Connor como Habermas se equivocaron al diagnosticar las posibles salidas a la crisis de los Estados del Bienestar. Ambos planteaban que ni la subida de impuestos ni la reducción de servicios sociales solucionaría la crisis, sino por el contrario la agravaría, pues llevarian a un descontento generalizado. Pero como apunta Vallespín, aquélla ha sido la solución por la que han optado "la mayoría de las sociedades industriales avanzadas, sin que sus gobiernos se vieran afectados por ningún tipo de déficit de legitimación ni 'revuelta' de ninguna clase": Vallespín. 139 . 
4. Tampoco puede olvidarse que estos derechos no tienen un carácter absoluto para el constitucionalismo. De hecho, no son inherentes a la idea de Constitución, por lo que es perfectamente concebible una Constitución sin derechos sociales. Más aun, las Constituciones de mayor relevancia en el mundo, como la inglesa, la norteamericana e incluso la alemana, no cuentan con derechos sociales.

5. Y en último término existe otra limitante intrínseca al concepto derechos sociales. Estos derechos se caracterizan por el objetivo que persiguen: mejorar las condiciones materiales de vida y lograr una igualdad material entre los hombres, que es a su vez la fuente inspiradora de todo el constitucionalismo social. Dichas metas son antes que nada objetivos políticos, a los que el Derecho a lo más puede servir de instrumento para alcanzarlos. Pero como indica $\mathrm{Haba}$, si bien los ideales que representan los derechos sociales pueden cumplir un papel importante como "motivaciones de la organización social", no debe perderse de vista que, por ser ideales, no garantizan el éxito ${ }^{82}$.

El sentido común y el realismo nos dicen que si bien esos ideales son una aspiración loable, su consecución resulta irrealizable. $Y$ es que, como apunta Pereira Menaut, la Política no lo puede todo, de modo que "no se puede esperar de ella milagros, ni en lo colectivo ni en lo personal" ${ }^{83}$. Y si la Política es limitada con mayor razón lo es el Derecho, del que no se puede pretender obtener aquello que ni siquiera la Política es capaz de dar. Pedirle al Derecho lo que no le es propio resulta inadecuado ${ }^{\mathbf{8 4}}$, más aun cuando lo pedido es además utópico. Incurrir en tal error conlleva el grave riesgo de que el hombre pierda confianza en el Derecho.

Por eso la "secularización de la caridad" por medio del Derecho y la "función promocional del Derecho" ${ }^{85}$ constituyen objetivos no muy apegados a la realidad, al pretender del Derecho cuestiones que no le son propias. Como destaca Haba, la realidad no depende o sólo depende secundariamente "de las formulaciones jurídicas respectivas".

Y esto suele ser olvidado por los juristas que son víctimas del normativismo, "una especie de enfermedad profesional que muy a menudo afecta el pensamiento de los juristas -y no pocas veces es así cuando más 'técnico' lo consideran-, hace que ellos caigan, con especial facilidad, en ilusiones que tienen que ver básicamente con unos expedientes harto comunes en las formas populares de pensar: la 'magia verbal' (imaginarse que cierto 'decir' conlleva el 'hacer') y el wishful thinking (pensamiento por deseos). Son modalidades típicas del fenómeno típico general que Freud denominó la 'omnipotencia de las ideas'"186.

\footnotetext{
${ }^{82}$ Haba, 66.

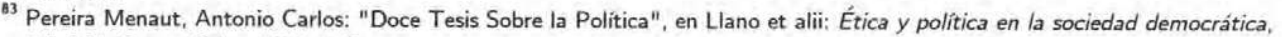
Madrid, Espasa-Calpe, 1981, 143.

${ }^{34}$ Sergio Cotta recuerda que si bien hoy en día la mayor parte del Derecho es expresión de una voluntad política, ello no significa que el Derecho mismo sea Política; en ¿Qué es el Derecho?, Madrid, Rialp, 1993, 20.

${ }^{85}$ Expresiones usadas por Peces-Barba en "El estado social de derecho", diario ABC, Madrid, edición de 30 de abril de $1993,3$.

${ }^{86}$ Haba, 68-69.
} 
Y así, el normativismo conduce a "concebir el Derecho como un mundo semántico autosuficiente; mundo que tiene -se presupone- la capacidad, por añadidura, de imponerse per se a las realidades sociales" ${ }^{187}$.

A estas alturas no es difícil entender el motivo por el que Barcellona califica a los derechos sociales de "derechos imperfectos". Como apunta el profesor italiano, "su realización, la naturaleza y alcance de su realización dependen de opciones políticas y de política económica; no son definidos de una vez por todas, sino que dependen de las relaciones de las fuerzas que luchan para procurarse una mayor cantidad de recursos. En estos términos, se podría decir que los derechos sociales son la cara de la política social que es realizada por un gobierno y que son (como tales) una variable dependiente del proceso económico, de sus criterios de cálculo y de la autonomía de sus lógicas" ${ }^{88}$.

Por todo esto es fácil comprender por qué Konrad Hesse se ha declarado en contra de la posible introducción en la Constitución alemana de preceptos programáticos sobre vivienda, empleo o medio ambiente. El destacado tratadista y exmiembro del Tribunal Constitucional germano sostiene que preceptos de este tipo suscitan expectativas: "Se leen en la Constitución y a continuación, lógicamente, hay que preguntarse: ¿Qué hay de las viviendas?, con el consiguiente efecto disfuncional si dichas expectativas no se ven cumplidas. La Constitución no debe prometer lo que no es capaz de cumplir". Y agrega que la Constitución "no es un programa político; al pretender convertirla en tal, se debilita el poder del legislador y se fuerza la capacidad de la Constitución" ${ }^{89}$.

\section{Consideraciones finales.}

Todo lo dicho en este trabajo no significa que el autor de estas líneas sea un liberal insolidario, indiferente a los problemas sociales. De hecho pienso que el Estado no puede permanecer al margen de éstos, sino que debe darles solución. $Y$ es que, a pesar de lo que puedan decir las modas neoliberales, el mercado no lo puede todo, ni es un dios. Pero esto no tiene por qué llevar a transformar las constituciones en programas de política social, pues la Constitución no fue inventada para eso, sino para limitar el poder. Por lo demás, los países con los modelos de asistencia social más admirados no cuentan con derechos sociales en sus constituciones. Tal es el caso de Suecia, Gran Bretaña, Canadá y Francia.

Pero además, por mucho que una Constitución pueda contener derechos sociales, ello no significa que el país respectivo sea más solidario y tenga menos diferencias sociales, pues las constituciones no producen milagros. Es más, su inclusión

87 Ibid., 69.

${ }^{88}$ Barcellona, Pietro: "Los sujetos y las normas. El concepto de estado social", en Olivas et alii, Problemas de legitimación en el estado social, Madrid, Trotta, 1991, 34. Estas características destacadas por el profesor italiano determinan que la constitucionalización de los derechos sociales se agote en la pura enunciación de cada derecho, y que su desarrollo e implementación se encomiende al legislador. Gerardo Ruiz-Rico critica que el desarrollo de los derechos sociales contemplados en las constituciones sea encomendado por éstas al legislador, como facultad discrecional. A su juicio esto conduce a una "sensación de 'fraude' producida por el Estado de Derecho", pues si bien los derechos se constitucionalizan, no gozan de efectivas garantías; en "Fundamentos sociales y políticos en los derechos sociales de la Constitución Española", Revista de Estudios Políticos 71. Madrid, 1991, 195.

${ }^{89}$ Cruz Villalón, Pedro: "La Ley Fundamental y la Unidad de Alemania. Una Conversación con Konrad Hesse", Anuario de Derecho Constitucional y Parlamentario 3, Murcia, 1993, 13-14. 
Revista de Derecho - Universidad Católica del Norte - Sede Coquimbo - 1997

en el texto constitucional puede originar efectos contraproducentes. $Y$ es que como su realización está sujeta a las condiciones económicas de cada momento, su eficacia no está siempre asegurada. de ahí que su constitucionalización puede tornarse en contra de la propia Constitución y del sistema democrático, cuando la contingencia económica impida hacerlos efectivos en algún momento. Ello puede conducir a que los ciudadanos se sientan defraudados por la Constitución y pierdan confianza en ella, lo que necesariamente repercutiría en la confianza en el régimen democrático ${ }^{90}$.

90 Todo ello pone en entredicho lo afirmado por Antonio Pérez Luño en el sentido de que "la proclamación de los derechos sociales supone una garantía para la democracia, esto es, para el efectivo disfrute por todos de las libertades personales, civiles y políticas", en Los derechos fundamentales, Madrid, Tecnos, 1984, 213. 